\title{
Salting-out of methane in the aqueous solutions of urea and sarcosine
}

\author{
M K DIXIT, ANUPAM CHATTERJEE and B L TEMBE* \\ Department of Chemistry, Indian Institute of Technology Bombay, Powai, Mumbai 400 076, India \\ e-mail: mayankd@chem.iitb.ac.in; bhilai.anupam@gmail.com; bltembe@chem.iitb.ac.in
}

MS received 14 December 2015; revised 1 February 2016; accepted 1 February 2016

\begin{abstract}
Hydrophobic association and solvation of methane molecules in aqueous solutions of urea and sarcosine (sa) have been studied using MD simulations. The potentials of mean force (PMFs) between methane molecules in water, water-sa, water-urea and water-urea-sa mixtures show an enhancement of methane association on the addition of these osmolytes. These observations are well supported by calculation of equilibrium constants. Calculation of thermodynamic parameters shows that the association of methane is stabilized by entropy and favored by enthalpy. The hydrophobic solvation of methane is stabilized by enthalpy and destabilized by entropy. The calculated solvation free energies of methane in these mixtures show that methane is less soluble in the mixtures of urea and sarcosine than in water. The solubility is the least in the water-urea-sa mixture. Analysis of distributions of solvent and co-solvent around methane suggests that the local densities of both urea and sarcosine are diminished around the methane in the mixtures of these osmolytes. The selective reduction of both urea and sarcosine from methane surface suggests that both urea and sarcosine push methane molecules towards water and increase the interaction between methane molecules i.e., salting-out of methane.
\end{abstract}

Keywords. Osmolytes; hydrophobic association; potentials of mean force (PMFs); preferential solvation; running coordination numbers (RCNs); excess coordination numbers (ECNs); preferential binding constants; solvation free energies; salting-out.

\section{Introduction}

Hydrophobic interactions are important in a variety of aqueous systems. ${ }^{1}$ In proteins, it is thought that hydrophobic associations among nonpolar moieties contribute significantly to the stability of the folded state. $^{2-5}$ The stabilities of proteins and non-polar solutes are affected by osmolytes. How protein structures and stabilities are affected in the presence of osmolytes including chemical denaturants and structure protectants is one of the most important questions in protein chemistry. ${ }^{6,7}$

Two naturally occurring osmolytes are urea and sarcosine or N-methylglycine. Urea drives the denaturing of proteins because of preferential binding of urea with its backbone and side chains. ${ }^{8}{ }^{8}$ Sarcosine is one of the most important protecting osmolytes. A lot of work have been done on the counteraction effect of sarcosine against the denaturing effect of urea. ${ }^{10-13}$ It is experimentally reported that if urea and protecting osmolytes are taken in 2:1 ratio then protecting osmolytes counteract the effect of urea. ${ }^{13}$

One of the first theories of hydrophobic interaction in aqueous solutions was given by Pratt and Chandler in their classic work. ${ }^{14}$ Force-biased Monte-Carlo

\footnotetext{
*For correspondence
}

simulations to understand hydrophobic association in aqueous solutions was performed by Berne et al., ${ }^{15}$ whose results were in good agreement with Pratt and Chandler's results. Methane-methane potentials of mean force (PMFs) were then calculated in other works using the Monte Carlo algorithm ${ }^{16,17}$ in infinitely dilute systems with two methane molecules.

Dang et al. ${ }^{18}$ performed one of the first molecular dynamics simulations to calculate methane-methane PMFs in water, in good agreement with previous Monte-Carlo simulations. Recently, Pratt et al. ${ }^{19}$ studied the effect of methane-water interactions on the PMF of two methane molecules in water and found that attractive solute-water interactions make a net repulsive contribution to these potentials of mean force.

To consider the effect of aqueous urea on hydrophobic association, Bennion and Daggett ${ }^{20}$ carried out molecular dynamics simulations of the protein chymotrypsin inhibitor in $8 \mathrm{M}$ aqueous urea solution. They found that urea molecules diminish the hydrophobic effect by altering water structure and thereby enhancing the solvation of hydrophobic groups. Since water structure is weakened by urea, water molecules become free to compete with intra-protein interactions aiding solvation of the unfolded state. Mountain and Thirumalai ${ }^{21}$ reported that direct interaction of urea with the site charges was the most important mechanism for the 
unfolding of hydrocarbon chains in aqueous urea solutions. With regard to stability of the folded structure of proteins, Bolen and co-workers studied the role of protein backbone solvation in the presence of structure protectant osmolytes. ${ }^{22-25}$ They argued that, due to differences in the hydration of backbone and osmolytes, the backbone of protein is osmophobic and it hides into the core of the folded protein. Molecular dynamics simulation techniques have also been used to study the role of trimethyl-N-oxide on the counteraction of urea-induced protein denaturation. ${ }^{26}$

Oostenbrink and van Gunsteren ${ }^{27}$ studied the aggregation of methane in water and the effect of urea on hydrophobic clustering by simulation for thirteen systems of different sizes and compositions. Their simulations showed that high urea concentration does not reduce hydrophobic interactions, rather it enhances the clustering of methane molecules only slightly.

Another MD simulation study ${ }^{28}$ investigated the influence of urea on pair interaction of hydrophobic moieties using different models of nonpolar neopentane molecules, water, and urea. Further studies from Zangi et al. ${ }^{29}$ showed that aqueous urea solution can unfold a hydrophobic polymer and this unfolding arises because of weakening of hydrophobic interactions between the polymer groups. The calculations of PMFs, however, do not reveal the mechanism by which urea and sarcosine influence hydrophobic interaction. These findings were also confirmed by recent computer simulations. ${ }^{30,31}$

Shimizu et al. ${ }^{32-34}$ have shown that the association of hydrophobic methane molecules is stabilized while the association of larger nonpolar solutes is destabilized by urea. Also, the clustering of methane is enhanced on the addition of urea into water because of favorable binding of methane with water. ${ }^{35,36}$

Paul et al. ${ }^{37}$ studied the association of methane in the presence of osmolytes urea and TMAO and found that that in binary aqueous urea solution, methane molecules are expelled by urea molecules, while in binary aqueous TMAO solution, methane prefers to interact more with TMAO than water.

Very recently, Narendra Kumar et al. ${ }^{38}$ studied the structure and effect of sarcosine on water and urea and found that sarcosine indirectly stabilizes protein by enhancing water-water structure and counteracts the effect of urea on hydrophobic association by directly interacting with it.

Garde et al. ${ }^{39}$ calculated entropic and enthalpic contributions to the free energy of methane-methane association in aqueous systems with varying ion concentrations and found that both the entropy and enthalpy at the contact minimum change negligibly with increasing pressure, whereas the solvent-separated configurations are stabilized at higher pressures by enthalpic contributions that prevail over slightly unfavorable entropic contributions. Pettitt et al., ${ }^{40}$ calculated enthalpy-entropy contributions to the free energy of methane association and found that the stabilizing contribution to contact pair formation comes from the entropic part, whereas enthalpic contribution largely determines the stability of the solvent separated configuration.

In the present work, we study the effect of osmolytes sarcosine and urea on the hydrophobic association of methane molecules in aqueous solutions and investigate the thermodynamics and preferential solvation of methane by water, sarcosine and urea in aqueous solutions of these osmolytes.

\section{Computational Methods}

\subsection{Molecular Dynamics Protocol}

All classical MD simulations were performed using the GROMACS package (version 4.6.4) ${ }^{41}$ in four different systems: water, water-urea, water-sarcosine and waterurea-sarcosine. We have computed electrostatic interactions using Particle Mesh Ewald method ${ }^{42}$ with a direct space cutoff of $1.0 \mathrm{~nm}$ and a grid spacing of $0.12 \mathrm{~nm}$. For van der Waals interactions, 12-6 Lennard Jones potential with a $1.0 \mathrm{~nm}$ cutoff has been used. Pressure of the systems is 1 bar and is held constant by using the Berendsen barostat. ${ }^{43}$ We have maintained the geometry of water, urea and sarcosine molecules during the simulations by using the LINCS algorithm. ${ }^{44}$ The temperature of the system is $298 \mathrm{~K}$ and it was kept constant using the velocity rescaling thermostat. ${ }^{45}$

The united atom model has been used for methane. SPCE model is used for water. ${ }^{46}$ We have used OPLS force field for methane and urea. ${ }^{47-53}$ The force field parameters of sarcosine are not defined in OPLS-AA

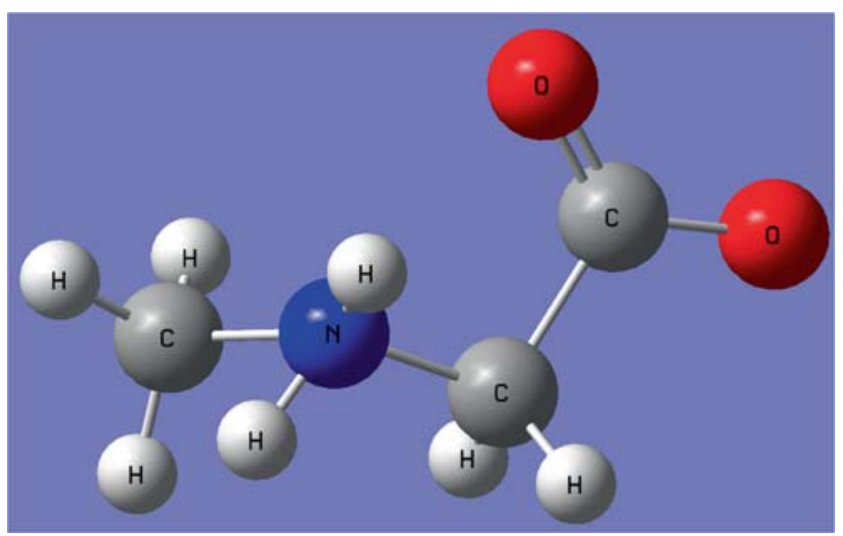

Figure 1. Structure of zwitterionic form of sarcosine with labels. 
Table 1. Details of the simulation boxes containing methane, water, urea and sarcosine. ${ }^{\mathrm{a}}$

\begin{tabular}{lcrrrr}
\hline System & $\mathrm{N}_{\mathrm{m}}$ & $\mathrm{N}_{\mathrm{w}}$ & $\mathrm{N}_{\mathrm{ua}}$ & $\mathrm{N}_{\mathrm{sa}}$ & $\mathrm{L}(\mathrm{nm})$ \\
\hline $\mathrm{I}_{\mathrm{w}}$ & 20 & 980 & 0 & 0 & 3.12 \\
$\mathrm{II}_{\mathrm{w}-\mathrm{sa}}$ & 20 & 905 & 0 & 75 & 3.32 \\
III $_{\mathrm{w}-\text { ua }}$ & 20 & 830 & 150 & 0 & 3.30 \\
IV $_{\text {w-ua-sa }}$ & 20 & 755 & 150 & 75 & 3.49 \\
\hline
\end{tabular}

${ }^{\mathrm{a}} \mathrm{I}_{\mathrm{w}}$ refers to water, $\mathrm{II}_{\mathrm{w}-\mathrm{sa}}$ refers to aqueous sarcosine, $\mathrm{III}_{\mathrm{w}-\mathrm{ua}}$ refer to aqueous urea and $\mathrm{IV}_{\mathrm{w}-\mathrm{ua}-\mathrm{sa}}$ refers to aqueous sarcosine-urea mixtures. $\mathrm{N}_{\mathrm{m}}, \mathrm{N}_{\mathrm{w}}, \mathrm{N}_{\mathrm{ua}}$, and $\mathrm{N}_{\mathrm{sa}}$ refer to numbers of methane, water, urea and sarcosine molecules, respectively, in each simulation box. $\mathrm{L}$ is the box length of the cubic simulation box.

force field. We have described sarcosine by taking the OPLS-AA force field parameters of similar groups such as $\alpha-\mathrm{C}$ of sarcosine using $\alpha-\mathrm{C}$ of glycine. Since the $\mathrm{HF} / 6-31 \mathrm{G}^{* *}$ basis of Gaussian 09 software package ${ }^{54}$ is used for calculating OPLS charges, ${ }^{55,56}$ we have used the same method for geometry optimization and the calculation of partial charges on sarcosine. The Electrostatic Potential (ESP) method ${ }^{57}$ has been used to derive the partial charges. The partial charges on sarcosine are given in table S1. A snapshot of sarcosine with atom labels is given in figure 1 .

Packmole software is used to generate the initial configuration of each system. ${ }^{58}$ Initially, MD simulations were performed for $50 \mathrm{~ns}$ in NVT ensemble for thermal equilibration of each system at 1 atm pressure and at a temperature of $298 \mathrm{~K}$. Subsequently, NPT simulations for $100 \mathrm{~ns}$ were carried out for the equilibration of the pressure of each system using the Berendsen barostat. Finally, we have generated trajectories of $100 \mathrm{~ns}$ for each system using NPT MD simulations by using Parrinello-Rahman pressure coupling. ${ }^{59,60}$ In each mixture, we have performed MD at three different temperatures: 278 K, 298 K and 318 K. From these trajectories, we have computed the potentials of mean force (PMFs) between methane molecules with the help of methanemethane pair correlation functions $[g(r)]$. Details of the simulation boxes containing methane, water, urea and sarcosine are given in table 1.

\subsection{Potentials of Mean Force}

Methane-methane PMFs have been calculated from

$$
W(r)=-k_{B} T \ln g(r)
$$

Where $k_{B}$ is the Boltzmann constant in $\mathrm{kJ} \mathrm{mol}^{-1}, T$ is the temperature in Kelvin and $g(r)$ is the methanemethane pair correlation function, calculated using a bin width of $0.01 \mathrm{~nm}$.

\subsection{Thermodynamics}

We have used a finite temperature difference method to calculate the entropy contributions at each methanemethane separation by the following formula. ${ }^{61}$

$$
\Delta S(\mathrm{r})=-\frac{W(r, T+\Delta T)-W(r, T-\Delta T)}{2 \Delta T}
$$

Here, $\Delta \mathrm{S}(\mathrm{r})$ is the entropy contribution at a methanemethane separation $r, W(r, T)$ is the potential of mean force between methane molecules at $r$, at temperature $\mathrm{T}$ and $\Delta T$ is the temperature difference.

The enthalpy contribution to the potential of mean force is obtained from

$$
\Delta H(r)=W(r)+T \Delta S(r)
$$

\subsection{Solvation Gibbs free energy of methane in water,} water-urea, water-sarcosine and water-urea-sarcosine mixtures

Ben-Naim ${ }^{62}$ has used Widom's potential distribution theorem ${ }^{63}$ to define the solvation free energy of a solute. The solute solvent binding interaction $\mathrm{B}_{\mathrm{s}}$ is established by inserting a test particle $\mathrm{S}$ at a random point in an $\mathrm{N}$ particle liquid configuration. It is the difference of the $\mathrm{N}+1$ and $\mathrm{N}$ particle potential energies, $\mathrm{B}_{\mathrm{s}}=\mathrm{U}_{\mathrm{N}+1}-$ $\mathrm{U}_{\mathrm{N}}$. The standard Gibbs free energy change $\left(\Delta \mathrm{G}^{*}\right)$ is calculated as follows.

$$
\Delta G^{*}=-R T \ln \left[\left\langle V \exp \left(-B_{s} / R T\right)\right\rangle_{N P T} /\langle V\rangle_{N P T}\right]
$$

Here, the ensemble average is taken over the solvent configurations at constant pressure $P$ and temperature $T$. In eq. 7, $V$ denotes the system volume and $\langle V\rangle_{N P T}$ its ensemble average at constant $P$ and $T$.

\subsection{Equilibrium constants}

We have calculated the equilibrium constants for methane molecules in water, water-sa, water-urea and water-urea-sa solutions. The equilibrium constant is defined as,

$$
\begin{gathered}
K_{\mathrm{eq}}=\frac{[S S M]}{[C M]} \\
{[C M]=4 \pi \int_{0}^{r_{1}} r^{2} e^{-W(r) / k_{B} T} d r} \\
{[S S M]=4 \pi \int_{r_{1}}^{r_{2}} r^{2} e^{-W(r) / k_{B} T} d r}
\end{gathered}
$$

where $K_{e q}$ is the equilibrium constant, [SSM] is the area $\left(\mathrm{nm}^{2}\right)$ under the curve between $\mathrm{r}_{1}$ (for transition state 1 , 
$\mathrm{TS} 1=0.58 \mathrm{~nm})$ and $\mathrm{r}_{2}$ (for TS2 $=0.89 \mathrm{~nm}$ ), $[\mathrm{CM}]$ is calculated as the area under the curve up to $\mathrm{r}_{1}$ (for TS1 $=0.58 \mathrm{~nm}), W(r)$, the PMF of methane molecules, $\mathrm{k}_{\mathrm{B}}$ is the Boltzmann's constant, $T$ is the temperature of the system and $r_{1}$ is the position of the first maximum and $r_{2}$ is the position of second maximum in the corresponding PMF curve.

\subsection{Preferential Solvation}

2.6a Running coordination numbers (RCNs) of water, urea and sarcosine molecules around methane: The running coordination numbers are defined as

$$
n_{\alpha \beta}=4 \pi \rho_{\beta} \int_{r_{1}}^{r_{2}} r^{2} g_{\alpha \beta}(r) d r
$$

where $n_{\alpha \beta}$ represents the number of atoms of type $\beta$ surrounding type $\alpha$ in a shell extending from $r_{1}$ to $r_{2}$ and $\rho_{\beta}$ is the number density of $\beta$ type species in the system. For the calculation of the first solvation shell coordination number, the value of $r_{1}$ is zero and the value of $r_{2}$ is the first minimum in the radial distribution function.

\section{6b Preferential binding of methane with urea and} sarcosine: To investigate the preferential solvation of methane in these systems, we calculate the excess coordination numbers of water, urea and sarcosine molecules around methane. The excess coordination number is defined as ${ }^{64}$

$$
N_{\alpha \beta}\left(r_{c}\right)=4 \pi \rho_{\alpha} \int_{0}^{r_{c}} r^{2}\left[g_{\alpha \beta}(r)-1\right] d r
$$

Here, $4 \pi \rho_{\alpha} r^{2} g_{\alpha \beta}(r)$ is the average number of $\alpha$ molecules around a $\beta$ molecule in a spherical shell of width $d r$ at radius $r$ and $4 \pi \rho_{\alpha} r^{2} d r$ is average number of $\alpha$ molecules in that spherical shell. Therefore, $N_{\alpha \beta}\left(r_{C}\right)$ represents the excess number of $\alpha$ molecules around a $\beta$ molecule measured up to $r=r_{c}$.

The KB theory gives relations between integrals of radial distribution functions and properties of solutions. The Kirkwood-Buff integral between species $i$ and $j$ is defined as ${ }^{64}$

$$
G_{i j}(r)=4 \pi \int_{0}^{r}\left[g_{i j}\left(r^{\prime}\right)-1\right] r^{\prime 2} d r^{\prime}
$$

The relation between preferential binding parameter $(v)$ and $\mathrm{KB}$ integrals for methane in the mixture of solvent and co-solvent is given by ${ }^{65}$

$$
v=\rho_{3}\left(G_{23}-G_{21}\right)(11)
$$

where $G_{23}$ (when $r$ in eq. 10 is $\infty$ ) is the $K B$ integral between solute (indexed as 2, methane) and cosolvent (3, urea or sarcosine), $\mathrm{G}_{21}$ (when $\mathrm{r}$ in eq. 10 is $\infty)$ is the KB integral between solute (2) and solvent (1, water) and $\rho_{3}$ is the number density of co-solvent (urea or sarcosine) in the mixtures. The positive value of $v$ indicates preferential binding of solute with co-solvent while negative value favors solvent, i.e., water.

\section{Results and Discussion}

\subsection{Potentials of Mean Force}

The potentials of mean force (PMFs) between methane molecules in water (black curve), water-sarcosine (red curve), water-urea (blue curve) and water-ureasarcosine mixtures (magenta curve) are given in figure 2 .

It is seen from figure 2 that there are three minima in each curve. The first minimum represents a contact minimum (CM) and subsequent minima correspond to solvent separated minima (SSM). In the third minimum, more than one solvent molecule may be inserted between the methane molecules. The contact minimum represents hydrophobic association and solvent separated minima represent the hydrophobic solvation of methane molecules in these mixtures. The differences between PMFs obtained from two sets of $50 \mathrm{~ns}$ simulations are less than $0.5 \mathrm{~kJ} \mathrm{~mol}^{-1}$ (figure $\mathrm{S} 1$, given in Supplementary Information).

The positions and free energies of contact minima, first transition states (TSs) and first solvent separated minima (second minima), first transition state barriers with respect to CM and with respect to SSM in

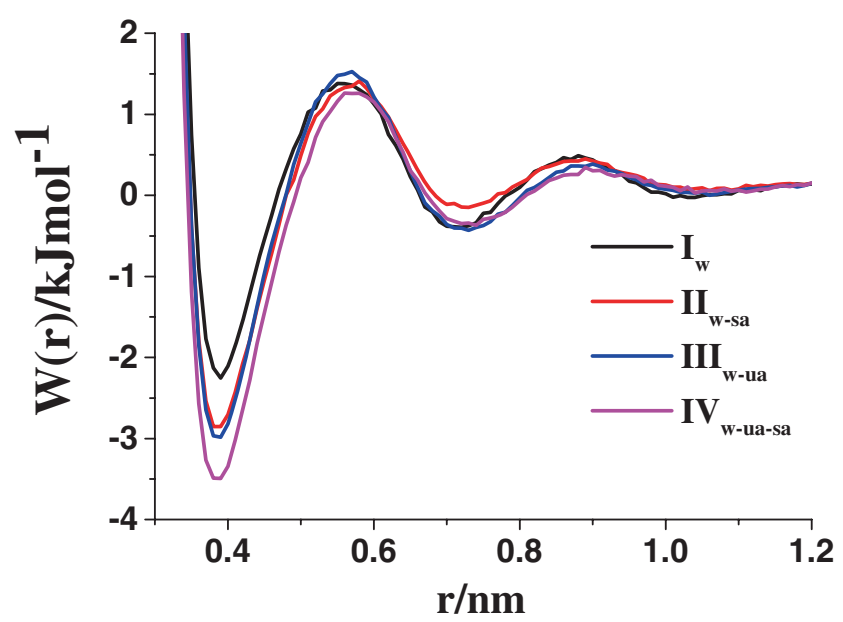

Figure 2. Potentials of mean force (PMFs) between methane molecules in $\mathrm{I}_{\mathrm{W}}$ (black curve), $\mathrm{II}_{\mathrm{w}-\mathrm{sa}}$ (red curve), $\mathrm{III}_{\mathrm{W}-\mathrm{ua}}$ (blue curve) and $\mathrm{IV}_{\mathrm{w}-\mathrm{ua}-\mathrm{sa}}$ mixtures (magenta curve). 

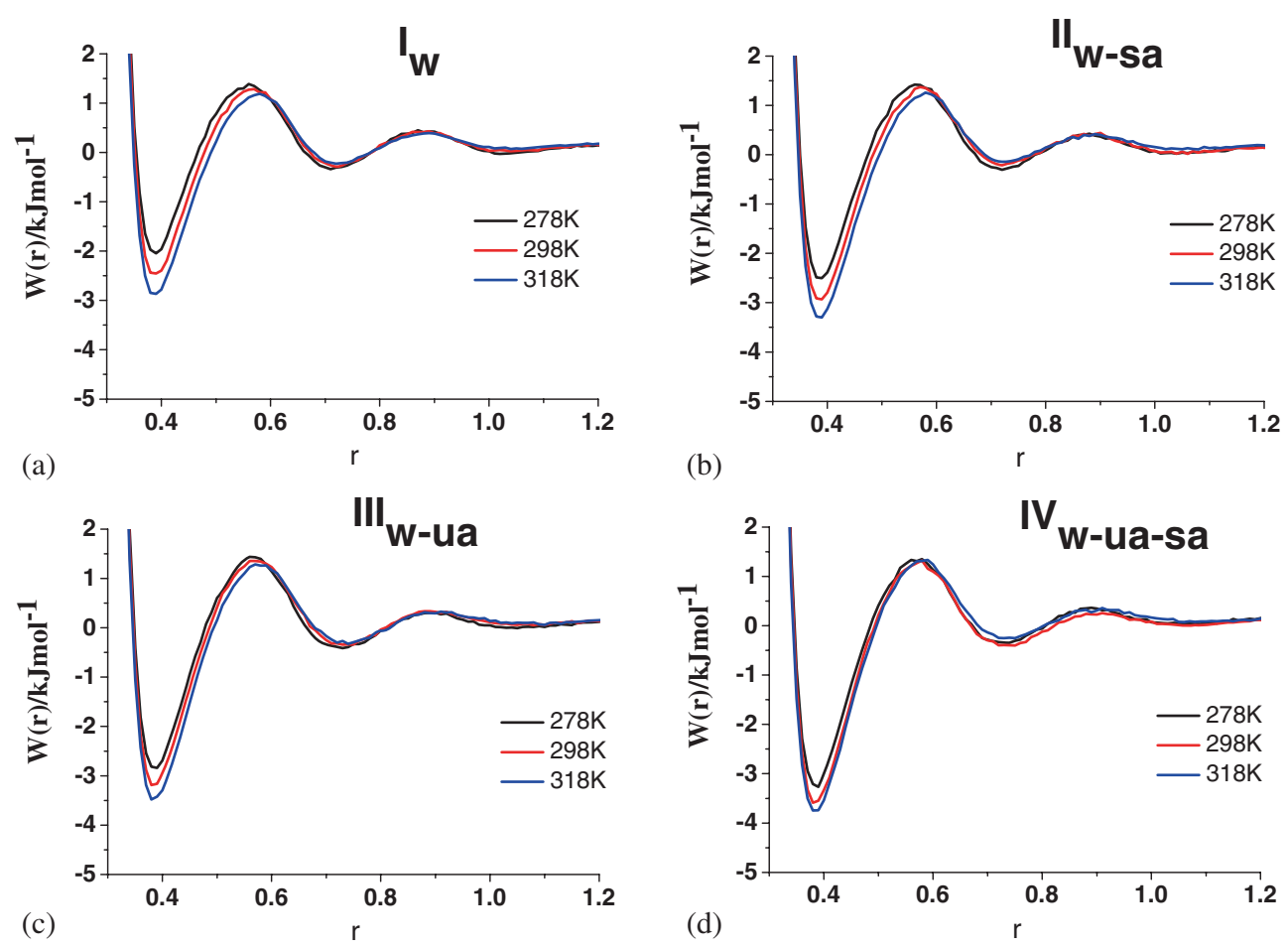

Figure 3. Potentials of mean force of methane molecules in $\mathrm{I}_{\mathrm{w}}, \mathrm{II}_{\mathrm{w}-\mathrm{sa}}, \mathrm{III}_{\mathrm{w}-\mathrm{ua}}$ and $\mathrm{IV}_{\mathrm{w}-\mathrm{ua}-\mathrm{sa}}$ solutions. PMFs at three temperatures are shown. PMF at $278 \mathrm{~K}$ (black curve), at $298 \mathrm{~K}$ (red curve) and at $318 \mathrm{~K}$ (blue curve).

water, water-sa, water-urea and water-urea-sa mixtures are given in table S2 (in Supplementary Information).

As we go from $\mathrm{I}_{\mathrm{w}}$ to $\mathrm{II}_{\mathrm{w}-\mathrm{sa}}$ solution, the depth of contact minimum changes from -2.3 to -2.9 (all energy values in $\mathrm{kJ} \mathrm{mol}^{-1}$ ) and the height of transition state barrier with respect to contact minimum changes from 3.7 to 4.3 . The depths of solvent separated minima change from -0.4 to -0.2 . From these differences, we note that hydrophobic association of methane increases and hydrophobic solvation marginally decreases on the addition of sarcosine to water. A similar trend have been observed in the water-glycine betaine solutions. ${ }^{66}$ As we go from water to water-urea mixture, the depth of $\mathrm{CM}$ changes from -2.3 to $-3.2 \mathrm{~kJ} \mathrm{~mol}^{-1}$ and the height of transition state barrier with respect to $\mathrm{CM}$ changes from 3.7 to $4.5 \mathrm{~kJ} \mathrm{~mol}^{-1}$. The depth of SSM changes from -0.4 to $-0.3 \mathrm{~kJ} \mathrm{~mol}^{-1}$. The hydrophobic association of methane molecules is enhanced on the addition of urea into water and the effect on hydrophobic solvation is marginal. As we add sarcosine (sa) into waterurea, the depth of contact minimum increases from -3.2 to $-3.6 \mathrm{kJmol}^{-1}$. The depth of SSM increases from -0.30 to $-0.40 \mathrm{~kJ} \mathrm{~mol}^{-1}$. The height of transition state barrier with respect to contact minimum increases from 4.5 to $4.9 \mathrm{~kJ} \mathrm{~mol}^{-1}$. The hydrophobic association of methane molecules is enhanced on the addition of sarcosine into water-urea mixture. The association of methane molecules is enhanced in all the mixtures, the effect on hydrophobic solvation is marginal when one considers only the barrier heights for solvation. The barrier heights for solvation (measured from the SSM state) in all the cases are $1.7 \pm 0.2 \mathrm{~kJ} \mathrm{~mol}^{-1}$.

Figure 3 shows the potentials of mean force of methane molecules in water $\left(\mathrm{I}_{\mathrm{w}}\right)(\mathrm{A})$, water-sa $\left(\mathrm{II}_{\mathrm{w}-\mathrm{sa}}\right)(\mathrm{B})$, water-urea $\left(\mathrm{III}_{\mathrm{w}-\mathrm{ua}}\right)(\mathrm{C})$ and water-urea-sa $\left(\mathrm{IV}_{\mathrm{w}-\mathrm{ua}-\mathrm{sa}}\right)(\mathrm{D})$ solutions at three temperatures: $278 \mathrm{~K}$, $298 \mathrm{~K}$ and $318 \mathrm{~K}$. On increasing the temperature, depth of $\mathrm{CM}$ increases, suggesting that methane association is favoured by entropy in all these mixtures.

\subsection{Equilibrium constants}

We have computed the equilibrium constants for methane molecules in water, water-sa, water-urea and water-urea-sa solutions. The equilibrium constants for methane molecules in these mixtures are given in table 2 .

It is seen from table 2 that the association of methane increases as we go from water to water-sa, water to water-urea and water to water-urea-sa. Both urea and sarcosine tend to enhance the association of methane. The association in the presence of both osmolytes seems to be the cumulative effect of the individual 
Table 2. Equilibrium constants for methane molecules in $\mathrm{I}_{\mathrm{w}}, \mathrm{II}_{\mathrm{w}-\mathrm{sa}}, \mathrm{III}_{\mathrm{w}-\mathrm{ua}}$ and $\mathrm{IV}_{\mathrm{w}-\mathrm{ua}-\mathrm{sa}}$ mixtures. [CM] is calculated as the area $\left(\mathrm{nm}^{2}\right)$ of Eq. (5) under the curve up to $\mathrm{r}_{1}$ (for TS1 $=0.58 \mathrm{~nm}$ ). [SSM] is the area of Eq. (6) under the curve between $r_{1}$ (for TS1 $=0.58 \mathrm{~nm}$ ) and $r_{2}$ (for TS2 $=0.89 \mathrm{~nm}$ ).

\begin{tabular}{lccc} 
Systems & {$[\mathrm{CM}]$} & {$[\mathrm{SSM}]$} & $\begin{array}{r}\text { Equilibrium constants } \\
([\mathrm{SSM}] /[\mathrm{CM}])\end{array}$ \\
\hline $\mathrm{I}_{\mathrm{w}}$ & 0.67 & 2.01 & 2.88 \\
$\mathrm{II}_{\mathrm{W}-\mathrm{sa}}$ & 0.87 & 1.95 & 2.23 \\
III $_{\mathrm{W}-\text { ua }}$ & 0.92 & 2.04 & 2.23 \\
IV $_{\text {w-ua-sa }}$ & 1.04 & 2.11 & 2.03 \\
\hline
\end{tabular}

osmolytes. As we add sarcosine to water-urea mixture, the equilibrium constant changes from 2.23 to 2.03 . The equilibrium constants, defined as $[\mathrm{SSM}] /[\mathrm{CM}]$ decrease as we go from only water to water-urea and to water-sa. When both osmolytes are added, the decrease in equilibrium constants is more than the decrease in individual cases.

These observations are supported by the calculations of thermodynamic quantities $(\Delta \mathrm{G},-\mathrm{T} \Delta \mathrm{S}$ and $\Delta \mathrm{H})$ which are shown in the next section.

\subsection{Entropy-Enthalpy Contributions to Free Energy}

The finite temperature difference method has been used to calculate the entropy contributions at each methane-methane separation. The thermodynamic quantities $(\Delta \mathrm{G},-\mathrm{T} \Delta \mathrm{S}$ and $\Delta \mathrm{H})$ are calculated as a function of methane-methane distance by using equations 2 and 3. We have shown the thermodynamic quantities $(\Delta \mathrm{G},-\mathrm{T} \Delta \mathrm{S}$ and $\Delta \mathrm{H})$ for the hydrophobic association and hydrophobic solvation of methane molecules as a function of methane-methane distance for the four mixtures in figure 4.

In $\mathrm{A}, \mathrm{B}, \mathrm{C}$ and $\mathrm{D}$ of figure 4 above, the black curve represents the potential of mean force $(\Delta G)$ between methane molecules, the red curve represents entropy contribution $(-\mathrm{T} \Delta \mathrm{S})$ to the PMFs and the blue curve represents the enthalpy contribution to the PMFs.

In all the four mixtures, the association between methane molecules is stabilized by entropy and the hydrophobic solvation is destabilized by entropy. Local minima in enthalpy also contribute favorably to both association and solvation of methane.

Contributions at the contact minimum as well as at the solvent separated minimum have been tabulated in table 3 .

We can notice from table 3 that on addition of urea to water, the entropy of the system at the methanemethane CM configuration decreases. This is most likely because of a decrease in the orientational entropy of water molecules in the system on addition of urea, as the degrees of freedom of water molecules are reduced because of water structuring around the urea molecules.
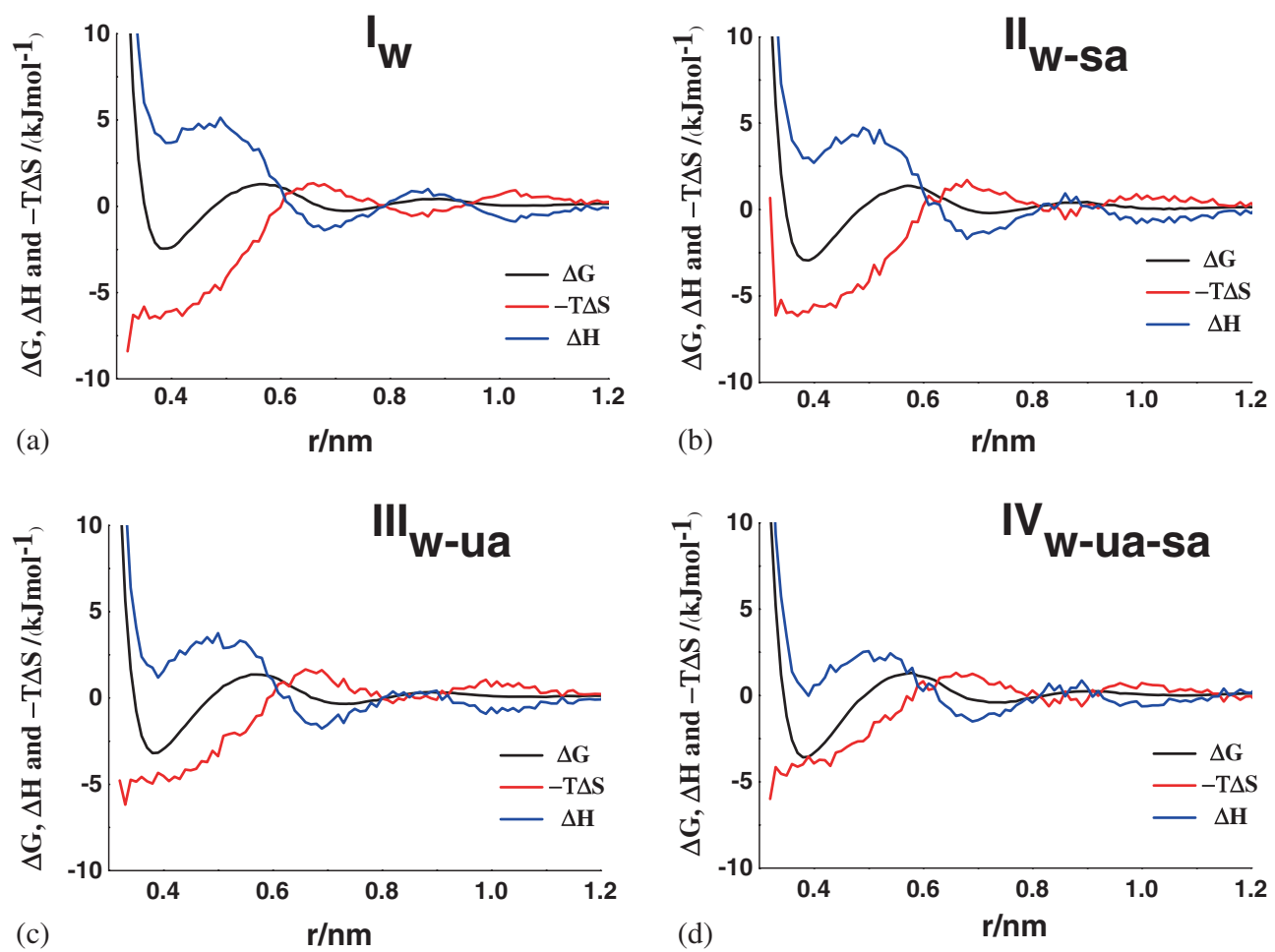

Figure 4. Thermodynamic quantities $(\Delta \mathrm{G},-\mathrm{T} \Delta \mathrm{S}$ and $\Delta \mathrm{H})$ for the hydrophobic association of methane molecules in $\mathrm{I}_{\mathrm{w}}(\mathrm{a}), \mathrm{II}_{\mathrm{w}-\mathrm{sa}}(\mathrm{b}), \mathrm{III}_{\mathrm{w}-\mathrm{ua}}(\mathrm{c})$ and $\mathrm{IV}_{\mathrm{w}-\mathrm{ua}-\mathrm{sa}}(\mathrm{d})$ solutions. 
Table 3. Enthalpy-entropy contributions to the PMF at CM and SSM states of methane in water, water-sarcosine, waterurea, and water-urea-sarcosine mixtures. $\Delta \Delta \mathrm{H}$ is the change in the enthalpy as we move from $\mathrm{I}_{\mathrm{W}} \rightarrow \mathrm{II}_{\mathrm{w}-\mathrm{sa}}$, or $\mathrm{II}_{\mathrm{w}-\mathrm{ua}}$ or $\mathrm{II}_{\mathrm{W}-\mathrm{ua}-\mathrm{sa}}$ at CM and SSM states of methane. $\Delta \Delta \mathrm{S}$ is the change in the entropy as we move from $\mathrm{I}_{\mathrm{w}} \rightarrow \mathrm{II}_{\mathrm{w}-\mathrm{sa}}$, or $\mathrm{II}_{\mathrm{w}-\mathrm{ua}}$ or $\mathrm{II}_{\mathrm{w}-\mathrm{ua}-\mathrm{sa}}$ at CM and SSM states of methane.

\begin{tabular}{|c|c|c|c|c|c|c|c|c|}
\hline \multirow[b]{2}{*}{ System } & \multicolumn{4}{|c|}{ Contact Minimum state } & \multicolumn{4}{|c|}{ Solvent separated minimum state } \\
\hline & $\begin{array}{c}\Delta H \\
\left(\mathrm{~kJ} \mathrm{~mol}^{-1}\right)\end{array}$ & $\begin{array}{c}\Delta \Delta H \\
\left(\mathrm{~kJ} \mathrm{~mol}^{-1}\right)\end{array}$ & $\begin{array}{c}-T \Delta S \\
\left(\mathrm{~kJ} \mathrm{~mol}{ }^{-1}\right)\end{array}$ & $\begin{array}{c}-T \Delta \Delta S \\
\left(\mathrm{~kJ} \mathrm{~mol}^{-1}\right)\end{array}$ & $\begin{array}{c}\Delta H \\
\left(\mathrm{~kJ} \mathrm{~mol}^{-1}\right)\end{array}$ & $\begin{array}{c}\Delta \Delta H \\
\left(\mathrm{~kJ} \mathrm{~mol}^{-1}\right)\end{array}$ & $\begin{array}{c}-T \Delta S \\
\left(\mathrm{~kJ} \mathrm{~mol}^{-1}\right)\end{array}$ & $\begin{array}{c}-T \Delta \Delta S \\
\left(\mathrm{~kJ} \mathrm{~mol}^{-1}\right)\end{array}$ \\
\hline$I_{w}$ & 3.8 & 0 & -6.1 & 0 & -0.9 & 0.0 & 0.6 & 0 \\
\hline $\mathrm{II}_{\mathrm{w}-\mathrm{sa}}$ & 2.8 & -1.0 & -5.8 & 0.3 & -1.4 & -0.5 & 1.2 & 0.6 \\
\hline $\mathrm{III}_{\mathrm{w}-\mathrm{ua}}$ & 1.3 & -2.5 & -4.9 & 1.2 & -1.4 & -0.5 & 1.1 & 0.5 \\
\hline $\mathrm{IV}_{\mathrm{w}-\mathrm{ua}-\mathrm{sa}}$ & 0.05 & -3.8 & -3.8 & 2.3 & -1.0 & -0.1 & 0.6 & 0.0 \\
\hline
\end{tabular}

This is further enhanced on the addition of sarcosine. However, when only sarcosine is added to $I_{w}$ mixture, the system entropy changes marginally. As we move from water to water-sarcosine and water to water-urea mixtures, enthalpy of the system decreases at the CM state. As we go from water to water-urea-sarcosine, there is a significant decrease in the enthalpy because of cumulative effect of urea and sarcosine. At SSM state, the changes in the entropy and the enthalpy are marginal as we add urea and sarcosine into water.

3.4 Solvation Gibbs free energy of methane in water, water-urea, water-sarcosine and water-urea-sarcosine mixtures

We have given the solvation free energies of methane in water $\left(\mathrm{I}_{\mathrm{w}}\right)$, water-sarcosine $\left(\mathrm{II}_{\mathrm{w}-\mathrm{sa}}\right)$, water-urea $\left(\mathrm{III}_{\mathrm{w}-\mathrm{ua}}\right)$ and water-urea-sarcosine $\left(\mathrm{IV}_{\mathrm{w}-\mathrm{ua}-\mathrm{sa}}\right)$ at three temperatures $278 \mathrm{~K}, 298 \mathrm{~K}$ and $318 \mathrm{~K}$ in table 4.

At room temperature, the solvation free energies of methane are 9.2, 9.5, 9.7 and $10.0\left(\mathrm{~kJ} \mathrm{~mol}^{-1}\right)$ in water, water-sarcosine, water-urea and water-ureasarcosine mixtures, respectively. These results suggest that methane is less soluble in the mixtures of osmolytes than in water. Solubility of methane in these mixtures favored by enthalpy and disfavored by entropy. In the presence of osmolytes, hydrophobic association of methane is enhanced which is supported by solvation free energies. The transfer free energies of methane from water to the mixtures of osmolytes with enthalpy and entropy components are given in table S3 and table S4 (given in Supplementary Information).

\subsection{Solvation structures and preferential solvation of methane molecules in the aqueous solutions of urea and sarcosine}

3.5a Radial distribution functions (RDFs or $g(r) s)$ : We have shown the radial distribution functions of methane with water, urea and sarcosine in water-sa (A), water-urea (B) and water-urea-sa solutions (C) in figure 5. The RDFs between $\mathrm{CH}_{4}-\mathrm{O}_{\mathrm{w}}, \mathrm{CH}_{4}-\mathrm{Me}_{\mathrm{sa}}$, and $\mathrm{CH}_{4}-\mathrm{C}_{\text {ua }}$ are represented by black, red and blue curves, respectively.

The RDFs of methane with each site of sarcosine (sa) in water-sa mixture are given in figure S2 (in Supplementary Information). It is observed that the local densities of the methyl group of sarcosine around methane is stronger in comparison to the local densities of other sites of sarcosine (figure S2). In watersa mixture (figure 5(a)), methane-sarcosine interaction is stronger than methane-water interactions. We have given the RDFs of methane with each site of urea in water-urea mixture in figure S3 (figure S3, in Supplementary Information). It is observed that the local density of carbon site of urea around methane is more than that of other sites of urea. In water-urea mixture (figure 5(b)), methane-water interaction is stronger than methane-urea interactions. The interaction of methane with water is enhanced in water-urea-sa mixture (figure $5(\mathrm{c})$ ).

Table 4. The solvation free energies (in $\mathrm{kJ} \mathrm{mol}^{-1}$ ) of methane in $\mathrm{I}_{\mathrm{w}}, \mathrm{II}_{\mathrm{w}-\mathrm{sa}}$, $\mathrm{III}_{\mathrm{w}-\mathrm{ua}}$ and $\mathrm{IV}_{\mathrm{w}-\mathrm{ua}-\mathrm{sa}}$ at three temperatures $278 \mathrm{~K}, 298 \mathrm{~K}$ and $318 \mathrm{~K}$.

\begin{tabular}{|c|c|c|c|c|c|}
\hline \multirow[b]{2}{*}{ Mixtures } & \multicolumn{3}{|c|}{$\Delta \mathrm{G}$} & \multirow[b]{2}{*}{$\Delta \mathrm{H}(298 \mathrm{~K})$} & \multirow[b]{2}{*}{$-\mathrm{T} \Delta \mathrm{S}(298 \mathrm{~K})$} \\
\hline & $278 \mathrm{~K}$ & $298 \mathrm{~K}$ & $318 \mathrm{~K}$ & & \\
\hline$I_{w}$ & $8.2( \pm 0.1)$ & $9.2( \pm 0.1)$ & $9.9( \pm 0.1)$ & -2.8 & 12.6 \\
\hline $\mathrm{II}_{\mathrm{w}-\mathrm{sa}}$ & $8.7( \pm 0.1)$ & $9.5( \pm 0.1)$ & $10.2( \pm 0.1)$ & -1.7 & 11.2 \\
\hline $\mathrm{III}_{\mathrm{w}-\mathrm{ua}}$ & $8.8( \pm 0.1)$ & $9.7( \pm 0.1)$ & $10.2( \pm 0.1)$ & -0.7 & 10.4 \\
\hline $\mathrm{IV}_{\mathrm{w}-\mathrm{ua}-\mathrm{sa}}$ & $9.1( \pm 0.2)$ & $10.0( \pm 0.1)$ & $10.8( \pm 0.1)$ & -2.7 & 12.7 \\
\hline
\end{tabular}



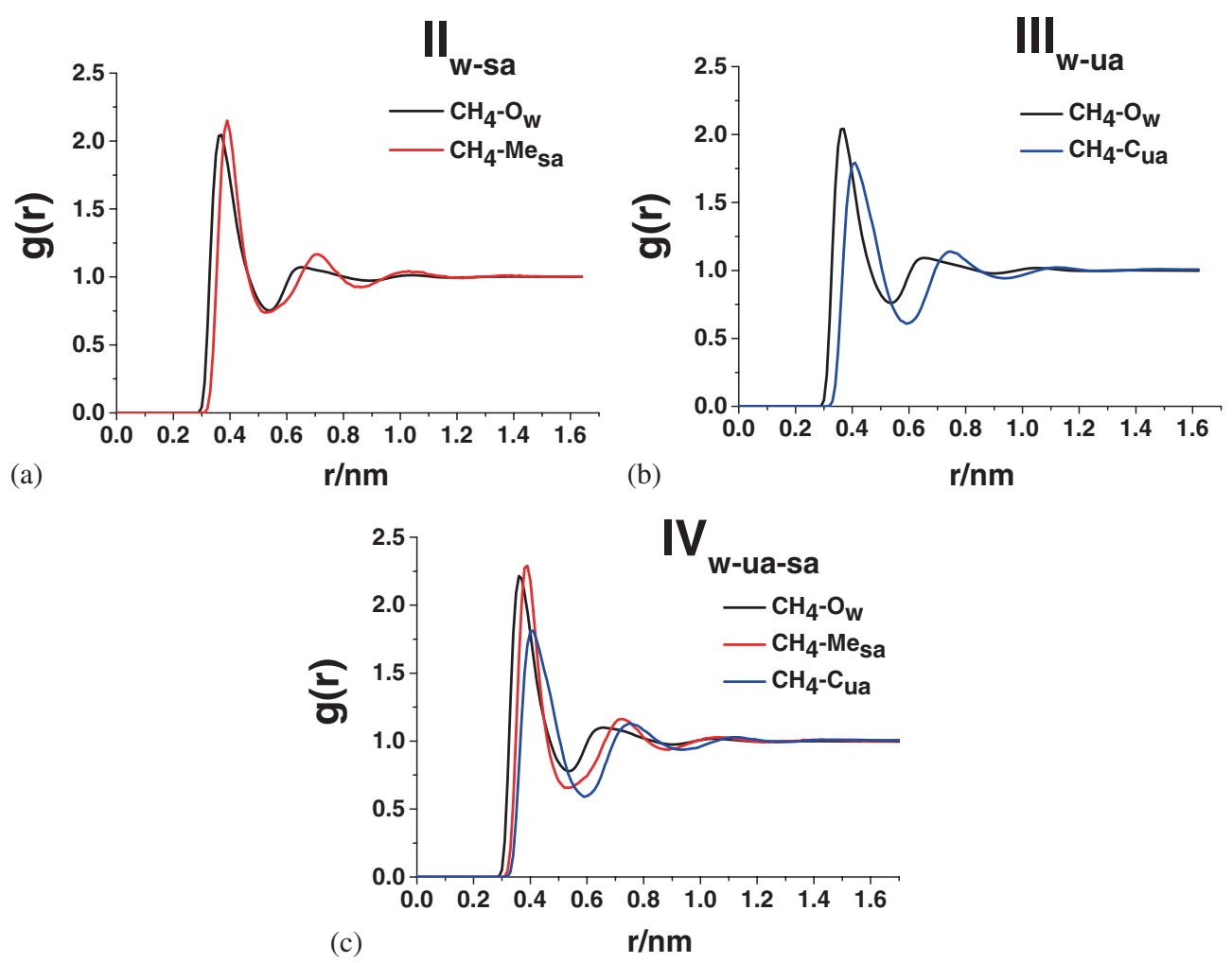

Figure 5. Radial distribution functions of methane with water, urea and sarcosine molecules in $\mathrm{II}_{\mathrm{w}-\mathrm{sa}}(\mathrm{a}), \mathrm{III}_{\mathrm{w}-\mathrm{ua}}$ (b) and $\mathrm{IV}_{\mathrm{w}-\mathrm{ua}-\mathrm{sa}}$ solutions (c).

To study the hydration of methane, it is important to study the effect of urea and sarcosine on water structure. Therefore, we have shown $\left(\mathrm{O}_{\mathrm{W}}-\mathrm{O}_{\mathrm{W}}\right) \mathrm{RDFs}$ (figure 6(a)) and $\left(\mathrm{O}_{\mathrm{w}}-\mathrm{H}_{\mathrm{w}}\right)$ RDFs (figure 6(b)) of water with water molecules in water (black line), watersa (red line), water-urea (blue line) and water-urea-sa (magenta line) solutions. The first peak of $\mathrm{O}_{\mathrm{W}}-\mathrm{O}_{\mathrm{W}}$ RDFs represents the hydrogen bonded first neighbor and the second peak represents the tetrahedrally located second neighbor. As we go from water to water-sa, the first peak height of $\mathrm{O}_{\mathrm{w}}-\mathrm{O}_{\mathrm{w}}$ RDFs increases from 2.9 to 3.4 which suggests that water-water interaction is enhanced. The peak height is 3.4 in water-urea solution which suggests that urea also strengthens the waterwater interaction. The first peak height of $\mathrm{O}_{w}-\mathrm{O}_{\mathrm{w}}$ radial distribution function is 4.0 in water-urea-sa mixture. In the $\mathrm{O}_{\mathrm{w}}-\mathrm{O}_{\mathrm{w}} \mathrm{rdf}$, the first valley becomes broader in the presence of urea and sarcosine which shows the
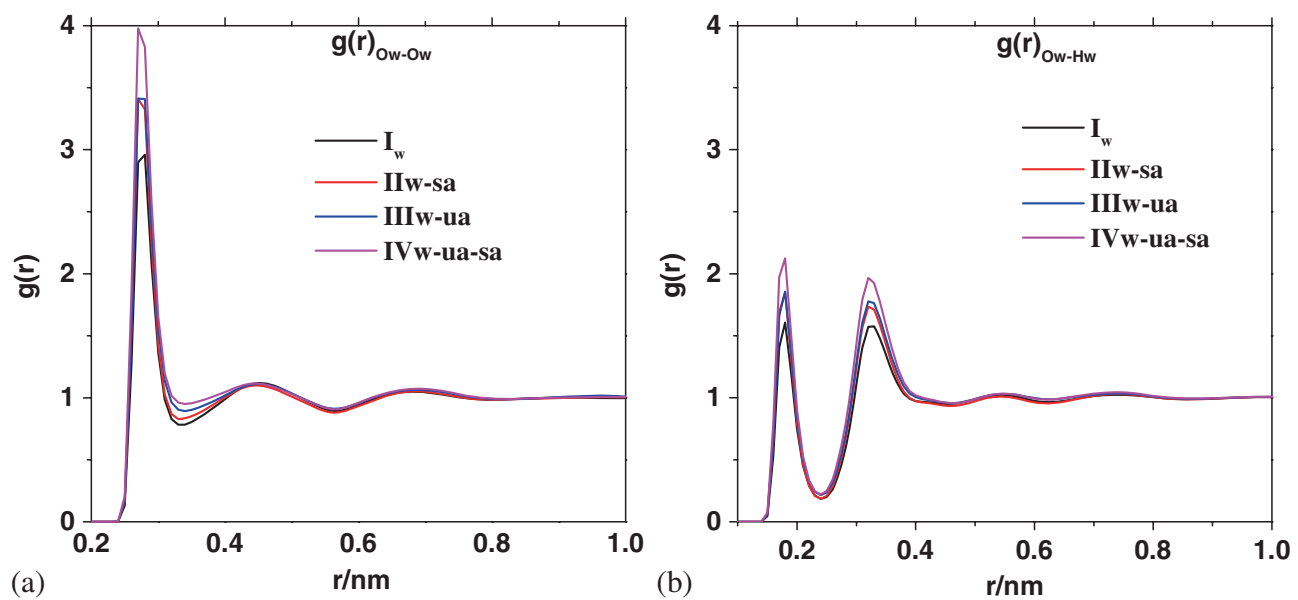

Figure 6. $\left(\mathrm{O}_{\mathrm{W}}-\mathrm{O}_{\mathrm{W}}\right) \mathrm{RDFs}(\mathrm{a})$ and $\left(\mathrm{O}_{\mathrm{W}}-\mathrm{H}_{\mathrm{w}}\right)$ RDFs (b) of water with water molecules in water (black line), water-sarcosine (red line), water-urea (blue line) and water-urea-sarcosine (magenta line) solutions. 

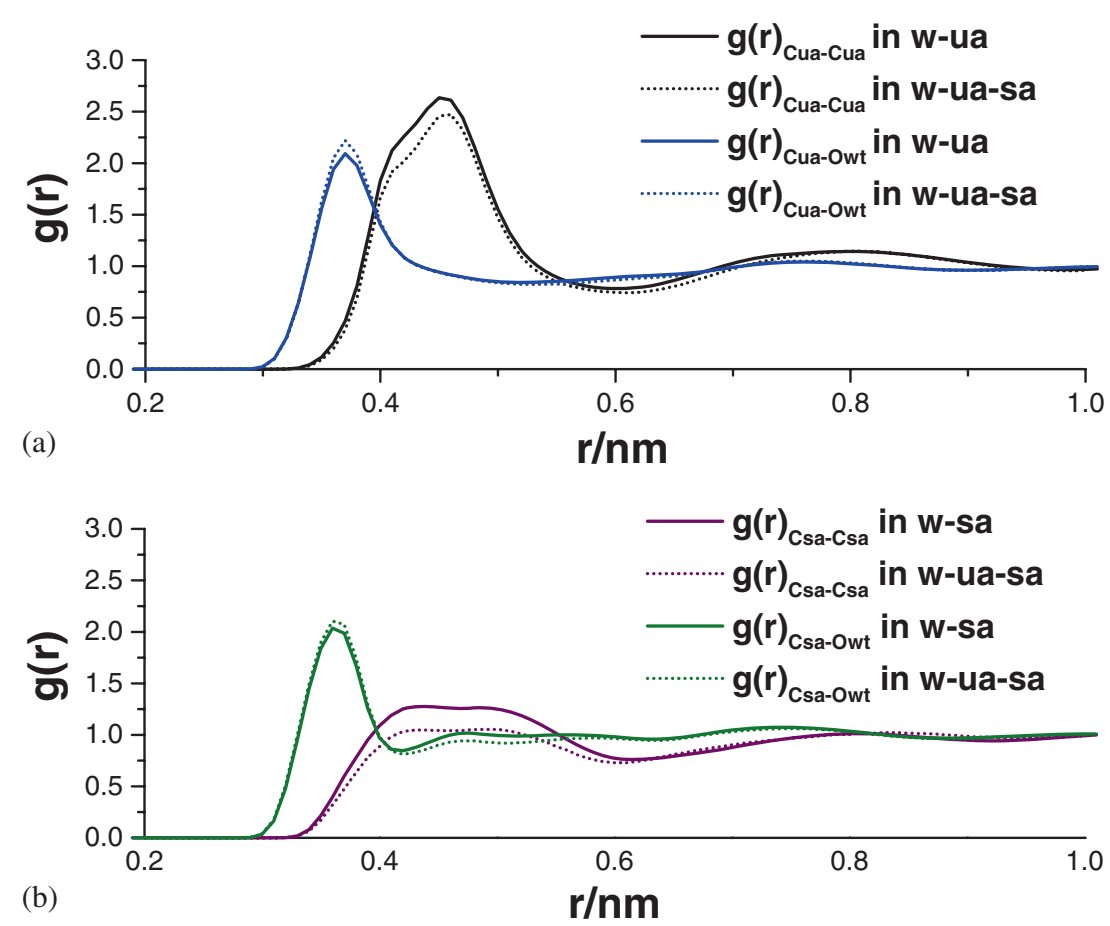

Figure 7. Radial distribution functions between urea-urea (solid black) in $\mathrm{III}_{\mathrm{w}-\mathrm{ua}}$, urea-urea (dotted black) in $\mathrm{IV}_{\mathrm{w}-\mathrm{ua}-\mathrm{sa}}$, urea-water (solid blue) in $\mathrm{III}_{\mathrm{w}-\text { ua }}$ and urea-water (dotted blue) in $\mathrm{IV}_{\mathrm{w}-\mathrm{ua}-\mathrm{sa}}$ (a). Radial distribution functions between sa-sa (solid purple) in $\mathrm{II}_{\mathrm{w}-\mathrm{sa}}$, sa-sa (dotted purple) in $\mathrm{IV}_{\mathrm{w}-\mathrm{ua}-\mathrm{sa}}$, sa-water (solid green) in $\mathrm{II}_{\mathrm{w}-\mathrm{sa}}$ and sa-water (dotted green) in $\mathrm{IV}_{\mathrm{w}-\mathrm{ua}-\mathrm{sa}}$ (b).

minor collapse of the second coordination shell of water around water. ${ }^{67}$

In the case of $\mathrm{O}_{\mathrm{w}}-\mathrm{H}_{\mathrm{w}}$ RDFs (figure 6(b)), the peak heights of first and second peak are enhanced in presence of urea and sarcosine. Therefore, the addition of osmolytes alter the water-water coordination structures beyond the first coordination shell. The potentials of mean force (PMFs) between water molecules in water (black curve), water-sarcosine (red curve), water-urea (blue curve) and water-urea-sarcosine mixtures (magenta curve) are given in figure S4 (in Supplementary Information) which supports that water-water interaction is enhanced.

The RDFs between the sites of co-solvents, and cosolvents and solvents are shown in figure 7. The RDFs between urea-urea in water-urea (solid black) and in water-urea-sa (dotted black), urea-water in water-urea (solid blue) and in water-urea-sa (dotted blue) are shown in figure 7(a). The RDFs between sa-sa in watersa (solid purple) and in water-urea-sa (dotted purple), sa-water in water-sa (solid green) and in water-urea-sa (dotted green) have been shown in figure 7(b).

The first peak heights of radial distribution functions of methane-methane, methane-water, methanesa, methane-urea, water-water, urea-urea, urea-water, sarcosine-sarcosine and sarcosine-water in water, water-sarcosine, water-urea and water-urea-sarcosine mixtures are given in table 5.

On the addition of sarcosine to water-urea mixture, urea-water interactions are enhanced (table 5).

Table 5. The heights of the first peaks of radial distribution functions of methane-methane, methane-water, methane-sa, methane-urea, water-water, urea-urea, urea-water, sarcosine-sarcosine and sarcosine-water in $\mathrm{I}_{\mathrm{w}}, \mathrm{II}_{\mathrm{w}-\mathrm{sa}}, \mathrm{III}_{\mathrm{w}-\mathrm{ua}}$ and IV $\mathrm{IV}_{\mathrm{w}-\mathrm{ua}-\mathrm{sa}}$ mixtures.

\begin{tabular}{lcccccccccc}
\hline & \multicolumn{7}{c}{ Heights of radial distribution functions } \\
\cline { 2 - 8 } Systems & $\mathrm{CH}_{4}-\mathrm{CH}_{4}$ & $\mathrm{CH}_{4}-\mathrm{O}_{\mathrm{W}}$ & $\mathrm{CH}_{4}-\mathrm{Me}_{\mathrm{sa}}$ & $\mathrm{CH}_{4}-\mathrm{C}_{\mathrm{ua}}$ & $\mathrm{O}_{\mathrm{w}}-\mathrm{O}_{\mathrm{w}}$ & $\mathrm{C}_{\mathrm{ua}}-\mathrm{C}_{\mathrm{ua}}$ & $\mathrm{C}_{\mathrm{ua}}-\mathrm{O}_{\mathrm{w}}$ & $\mathrm{C}_{\mathrm{sa}}-\mathrm{C}_{\mathrm{sa}}$ & $\mathrm{C}_{\mathrm{sa}}-\mathrm{O}_{\mathrm{w}}$ \\
\hline $\mathrm{I}_{\mathrm{w}}$ & 2.7 & 1.9 & - & - & 2.9 & - & - & \\
$\mathrm{II}_{\mathrm{w}-\mathrm{sa}}$ & 3.3 & 2.0 & 2.1 & - & 3.4 & - & - & 1.3 & 2.0 \\
$\mathrm{III}_{\mathrm{w}-\text { ua }}$ & 3.6 & 2.0 & - & 1.8 & 3.4 & 2.6 & 2.1 & 2.2 & 1.0 \\
$\mathrm{IV}_{\mathrm{w}-\text { ua-sa }}$ & 4.1 & 2.2 & 2.3 & 1.8 & 4.0 & 2.5 & 2.1 \\
\hline
\end{tabular}


Therefore, the availability of urea molecules to solvate methane is reduced. As we add urea into watersa mixture, the interactions between sarcosine and water molecules are enhanced (figure S5 of supplementary information). Hence, the preferential solvation of methane by sarcosine is diminished.

The first peak height of methane-sa RDF is 2.3 and methane-urea RDF is 1.8 (system IV $_{\text {w-ua-sa }}$ ) which suggests preferential solvation of methane by sarcosine over urea.

The computed values of running coordination numbers of water, urea and sarcosine molecules in the first coordination shell of methane are also supporting the findings, described in section $3.5 \mathrm{~b}$.

\section{5b Running Coordination numbers (RCNs) of} water, urea and sarcosine molecules around methane molecules: We have given the running coordination numbers of water, urea and sarcosine in the first coordination shells of methane in water, water-sa, water-urea and water-urea-sa mixtures in table 6.

As we go from $\mathrm{I}_{\mathrm{w}}$ to $\mathrm{II}_{\mathrm{w}-\mathrm{sa}}$, the value of $\mathrm{N}_{\mathrm{w}} / \mathrm{N}_{\mathrm{sa}}$ is 12.9 in the first coordination shell of methane and 12.0 in the bulk which suggests that methane has a preference for water molecules. In $\mathrm{III}_{\mathrm{w}-\mathrm{ua}}$, the value of $\mathrm{N}_{\mathrm{w}} / \mathrm{N}_{\mathrm{ua}}$ is 6.6 in the first coordination shell of methane and 5.5 in the bulk which suggests that methane is preferentially solvated by water molecules.

In water-urea-sa mixture, the $\mathrm{N}_{\mathrm{w}} / \mathrm{N}_{\mathrm{sa}}$ ratio is 11.7 in the first coordination shell of methane and 10 in the bulk. The $\mathrm{N}_{\mathrm{w}} / \mathrm{N}_{\text {ua }}$ ratio is 6.2 in the first coordination shell of methane and 5.0 in the bulk. These results also indicate that methane is preferentially solvated by water over sarcosine and urea. The value of $\mathrm{N}_{\mathrm{ua}} / \mathrm{N}_{\mathrm{sa}}$ is 1.9 in the first coordination shell of methane and 2.0 in the bulk, indicating a marginal domination of sa over urea in the coordination shell. 3.5c Preferential binding parameter (v) of methane with urea and sarcosine: To investigate the preferential solvation of methane in these systems, we calculate the excess coordination numbers of water, urea and sarcosine molecules around methane.

The excess coordination numbers (ECNs) of water, urea and sarcosine molecules around methane in water (A), water-sa (B), water-urea (C) and water-urea-sa (D) solutions are given in figure S6 (in Supplementary Information).

We have also calculated preferential binding parameters $(v)$ for methane in water-sarcosine, water-urea and water-sarcosine-urea solutions. The preferential binding constants of methane with sarcosine in water-sa mixture and with urea in water-urea mixture are given in table 7.

The values of preferential binding constants $(v)$ support a preference for water in all the mixtures. The first two rows of table 7 refer to binary mixtures (water-sa and water-urea) containing methane while rows 3 and 4 refer to the ternary mixture (water-urea-sa). In row 3 of table 7,v is calculated by taking species 3 to be sarcosine in eq. 11 . In row 4 , species 3 is urea. We see that whenever there is a presence of urea the values of $v$ are more negative than in the solutions wherein there is only sarcosine or when the solution contains both sarcosine and urea. The larger values of preferential binding parameters may be due to the strong structure breaking property of urea in water, which enhances the interaction of methane with water.

The negative values of preferential binding constants support that both urea and sarcosine push methane towards water. Therefore, aggregation of methane molecules is enhanced and there are salting-out of methane in the mixtures of urea and sarcosine.

The local correlations between solution components and salting-out thermodynamics can be adequately explained by calculating the quantity $\mathrm{G}_{21}(\mathrm{r})-\mathrm{G}_{23}(\mathrm{r})$

Table 6. Running coordination numbers in the first coordination shells of methane in the presence of osmolytes. $\mathrm{N}_{\mathrm{w}}, \mathrm{N}_{\mathrm{sa}}$ and $\mathrm{N}_{\mathrm{ua}}$ represent the number of water, sarcosine and urea molecules, respectively. The values in the brackets are the ratios in the bulk (bulk here, means the total system including the solvation shells). The cut-off for the first coordination shell of methane is $0.66 \mathrm{~nm}$ for all the mixtures.

\begin{tabular}{lcccccr}
\hline & \multicolumn{6}{c}{ Running coordination numbers in the first coordination shell of methane } \\
\cline { 2 - 7 } Systems & $\mathrm{N}_{\mathrm{w}}$ & $\mathrm{N}_{\mathrm{sa}}$ & $\mathrm{N}_{\text {ua }}$ & $\mathrm{N}_{\mathrm{w}} / \mathrm{N}_{\mathrm{ua}}$ & $\mathrm{N}_{\mathrm{w}} / \mathrm{N}_{\mathrm{sa}}$ & $\mathrm{N}_{\text {ua }} / \mathrm{N}_{\mathrm{sa}}$ \\
\hline $\mathrm{I}_{\mathrm{w}}$ & 36.0 & & & & & \\
$\mathrm{II}_{\mathrm{w}-\mathrm{sa}}$ & 28.3 & 2.2 & & & 12.9 & \\
$\mathrm{III}_{\mathrm{w}-\text { ua }}$ & 26.4 & & 4.0 & 6.6 & $\mathbf{( 1 2 . 0 )}$ & \\
$\mathrm{IV}_{\mathrm{w}-\text { ua-sa }}$ & 21.2 & 1.8 & 3.4 & $\mathbf{( 5 . 5 )}$ & & \\
& & & & $\mathbf{( 5 . 0 )}$ & $\mathbf{( 1 0 )}$ & $\mathbf{( 2 . 0 )}$ \\
\hline
\end{tabular}


Table 7. The preferential binding constants $(v)$ of methane with sarcosine in $\mathrm{II}_{\mathrm{w}-\mathrm{sa}}$ and with urea in $\mathrm{III}_{\mathrm{w}-\mathrm{ua}}$.

\begin{tabular}{lc}
\hline Systems & Preferential binding constants $(v)$ \\
\hline $\mathrm{II}_{\mathrm{w}-\mathrm{sa}}$ & -0.06 \\
$\mathrm{III}_{\mathrm{w}-\mathrm{ua}}$ & -0.87 \\
$\mathrm{IV}_{\mathrm{w}-\mathrm{ua}-\mathrm{sa}}$ & -0.26 (with sarcosine) \\
& -0.91 (with urea) \\
\hline
\end{tabular}

obtained using eq. 10 based on Kirkwood-Buff theory (also known as fluctuation theory of solutions). The theory relates integral over molecular distribution functions to particle number fluctuations. These quantities are given in figure 8.

For all the systems, we observe that $\left(\mathrm{G}_{21}(\mathrm{r})-\mathrm{G}_{23}(\mathrm{r})\right)>$ 0 (oscillating due to structural fluctuations) which suggests the preferential solvation of methane by water and salting-out of methane. In water-urea-sarcosine mixture, the values of $\left(\mathrm{G}_{21}(\mathrm{r})-\mathrm{G}_{23}(\mathrm{r})\right)$ are more positive compared to the other mixtures. Therefore, both urea and sarcosine push methane molecules into water and maximum salting-out of methane has been observed in $\mathrm{IV}_{\mathrm{w}-\mathrm{ua}-\mathrm{sa}}$.

3.6 Diffusional behavior of water molecules in the systems, $I_{w}, I I_{w-s a}, I I_{w-u a}$ and $I V_{w-u a-s a}$

The diffusion coefficients $(D)$ are calculated from the mean square displacements, using the Einstein's relation,

$$
D=\lim _{t \rightarrow \infty} \frac{\left\langle\left|r_{i}(t+\Delta t)-r_{i}(t)\right|^{2}\right\rangle}{6 t}
$$

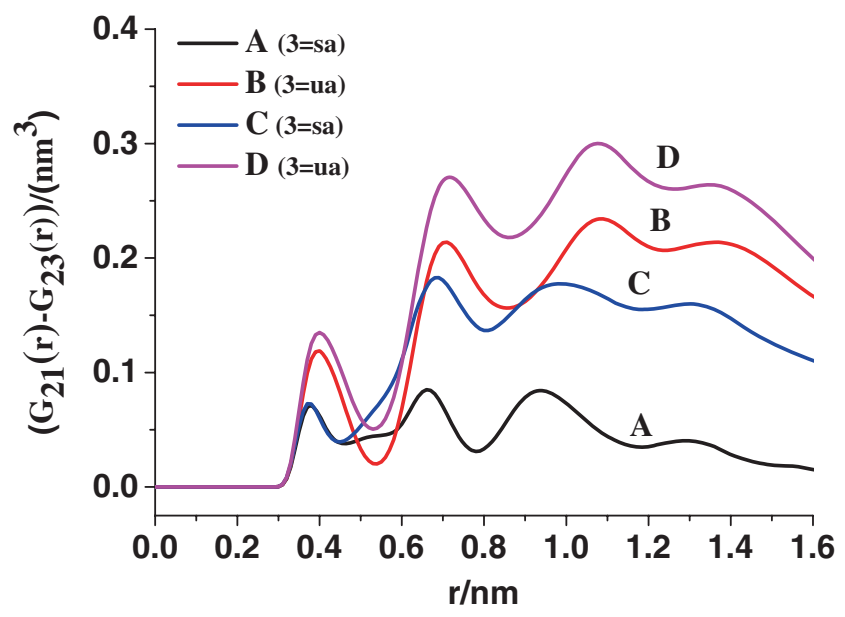

Figure 8. Running $\mathrm{G}_{21}(\mathrm{r})$ (methane-water KBIs) minus methane-cosolvent $\left(\mathrm{G}_{23}(\mathrm{r})\right)$ in water-sa $(A)$, water-urea $(B)$. Curves $C$ and D refer to water-urea-sa solutions. Subscript 1 refers to water, 2 refers to methane and 3 refers to urea or sa. In curve $C, 3$ refers to sa and in curve D, 3 refers to urea.
Table 8. Diffusion Coefficients (in $10^{-5} \mathrm{~cm}^{2} \mathrm{~s}^{-1}$ ) of water molecules in $\mathrm{I}_{\mathrm{w}}, \mathrm{II}_{\mathrm{w}-\mathrm{sa}}, \mathrm{III}_{\mathrm{w}-\mathrm{ua}}$ and $\mathrm{IV}_{\mathrm{w}-\mathrm{ua}-\mathrm{sa}}$.

\begin{tabular}{lc}
\hline System & Diffusion Coefficient (in $\left.10^{-5} \mathrm{~cm}^{2} \mathrm{~s}^{-1}\right)$ \\
\hline $\mathrm{I}_{\mathrm{w}}$ & $2.29( \pm 0.06)$ \\
$\mathrm{II}_{\mathrm{w}-\mathrm{sa}}$ & $1.14( \pm 0.05)$ \\
$\mathrm{III}_{\mathrm{w}-\mathrm{ua}}$ & $1.66( \pm 0.03)$ \\
$\mathrm{IV}_{\mathrm{w}-\mathrm{ua}-\mathrm{sa}}$ & $0.71( \pm 0.02)$ \\
\hline
\end{tabular}

where $r_{\mathrm{i}}(t)$ is the position of the $\mathrm{i}^{\text {th }}$ water molecule at time $t$.

We have studied the diffusional pattern of water molecules in these mixtures. It is observed that urea and sarcosine both tend to decrease the diffusion of water molecules. The diffusion coefficients of water molecules in the four mixtures are given in table 8 .

The values of diffusion coefficients are 2.29, 1.14, 1.66 and 0.71 (in $10^{-5} \mathrm{~cm}^{2} \mathrm{~s}^{-1}$ ) in water, watersarcosine, water-urea and water-urea-sarcosine mixtures. The diffusion of water molecules is less in the mixtures of these osmolytes suggesting that they strengthen the water-water interaction. The lower values of D in water-sarcosine and water-urea-sarcosine suggest strong association of sarcosine with water molecules (figure S5, Supplementary Information).

\subsection{Hydrogen-bonding properties of water-urea-sa solutions}

Hydrogen bonds in this study are characterized by the $\mathrm{H}$-acceptor distances that are less than $0.26 \mathrm{~nm}$ and the acceptor-H-donor angles greater than $130^{\circ}$. We have calculated the lifetimes of hydrogen bonds of water molecule in the mixtures of osmolytes. The computation of lifetimes of hydrogen bonds follows the work of Chandler et al. ${ }^{68}$ The fluctuation in hydrogen bond population is characterized by the following correlation functions $\mathrm{c}(\mathrm{t})$.

$$
c(t)=\langle h(0) h(t)\rangle /\langle h\rangle
$$

Here, $\mathrm{h}(\mathrm{t})$ is the hydrogen bond population operator. The value of the operator is 1 when two water molecules are hydrogen bonded and zero otherwise. $\mathrm{c}(\mathrm{t})$ is the probability that the hydrogen bond is intact between two water molecules at time $t$, given that the both water are hydrogen bonded at time zero. The rate of relaxation to equilibrium is given by

$$
r(t)=-d c / d t=-\langle\dot{h}(0)[1-h(t)]\rangle /\langle h\rangle
$$

Where, $r(\mathrm{t})$ is the average rate of change of hydrogenbond population (time dependent), $\dot{h}(0)=(d h / d t)_{t=0}$, (because $\langle h(0) \dot{h}(t)\rangle=-\langle\dot{h}(0) h(t)\rangle$ and $\langle\dot{h}(0)\rangle=0)$. 
The functions, $\mathrm{c}(\mathrm{t})$ and $r(\mathrm{t})$ will decay exponentially only if the lifetime distribution is exponential. The nonexponential relaxation of hydrogen bonding is because of the coupling between hydrogen bond population and diffusion. Two hydrogen bonded molecules can diffuse far away if hydrogen bond between them breaks and a broken hydrogen bond can reform if a molecule reverses its direction and diffuses back to its hydrogen bonded partner.

The probabilities $\mathrm{c}(\mathrm{t})$ and $\mathrm{n}(\mathrm{t})$ correspond to local population that can interconvert. Hence, the overall hydrogen bond kinetics is given by,

$$
d c / d t=-k c(t)+k^{\prime} n(t)
$$

Where $\mathrm{k}$ and $\mathrm{k}^{\prime}$ (unit is time ${ }^{-1}$ ) (time independent) are respective rate constants for the breaking and making of hydrogen bonds between a near-neighbor pair of water molecules, and $\mathrm{n}(\mathrm{t})$ is, $n(t)=\int_{0}^{t} d t^{\prime} k_{\text {in }}\left(t^{\prime}\right)$ and $k_{\text {in }}(t)=-\langle\dot{h}(0)[1-h(t)] H(t)\rangle /\langle h\rangle$. The physical meaning of $1 / \mathrm{k}$ is that of the average hydrogen-bond lifetime. $H(\mathrm{t})$ is unity if the oxygen-oxygen distance of two water molecules is less than $3.5 \AA$. The computed values of number of hydrogen bonds in the four mixtures are given in table 9.

As we go from water to the mixtures of osmolytes, the number of hydrogen bonds per water molecule decreases but the lifetimes of hydrogen bonds as well as bond dissociation energies of hydrogen bonds increase (the lifetimes of hydrogen bonds are given in table S5 and the bond dissociation energies of hydrogen bonds are given in table S6 of Supplementary Information) due to the strong association of water with osmolytes. There is a gradual decrease with temperature, as expected. The hydrogen bond time correlation functions $(\mathrm{c}(\mathrm{t})$ ) are given in figure S7 (Supplementary Information). In the mixtures of osmolytes, slower relaxations of $\mathrm{c}(\mathrm{t})$ have been observed in comparison to water. These calculations suggest that hydrogen bond strengths between water molecules are enhanced in the presence of osmolytes.

Table 9. Number of hydrogen bond per water molecule in the bulk in $\mathrm{I}_{\mathrm{w}}, \mathrm{II}_{\mathrm{w}-\mathrm{sa}}, \mathrm{III}_{\mathrm{w}-\mathrm{ua}}$ and $\mathrm{IV}_{\mathrm{w}-\mathrm{ua}-\mathrm{sa}}$.

\begin{tabular}{lccc}
\hline & \multicolumn{3}{c}{ Hydrogen bond per water molecule in the bulk } \\
\cline { 2 - 4 } Systems & $278 \mathrm{~K}$ & $298 \mathrm{~K}$ & $318 \mathrm{~K}$ \\
\hline $\mathrm{I}_{\mathrm{w}}$ & 3.7 & 3.6 & 3.5 \\
$\mathrm{II}_{\mathrm{W}-\mathrm{sa}}$ & 3.1 & 3.1 & 3.0 \\
$\mathrm{III}_{\mathrm{w}-\text { ua }}$ & 3.0 & 2.9 & 2.8 \\
$\mathrm{IV}_{\mathrm{w}-\text { ua-sa }}$ & 2.6 & 2.5 & 2.4 \\
\hline
\end{tabular}

\subsection{Discussion}

The addition of sarcosine to water shows enhanced hydrophobic association of methane in water-sarcosine. Although the depths of CM and SSM change, their locations are not altered. The two states are separated by an energy barrier of $1.4 \mathrm{~kJ} \mathrm{~mol}^{-1}$ (figure 2). The contact minimum is dominated by entropy and favored by enthalpy, because, when methane molecules approach towards contact minima, there is a removal of water and sarcosine molecules from the coordination shell of methane. When the CM is approached from the transition state, the entropy contribution monotonically increases, while the enthalpy contribution initially increases and finally reaches a local minimum at the CM. The solvent separated minimum is favored by enthalpy and disfavored by entropy. At SSM, enthalpy and entropy contributions are very close to each other.

In water-sarcosine mixture, methane prefers methane over water. The analysis of RDFs by KB integrals suggests preferential solvation of methane by water. Effects of addition of protecting osmolytes such as TMAO on hydrophobic interactions of methane have been reported earlier. ${ }^{37}$ It is worth mentioning that TMAO, glycine-betaine and sarcosine belong to the same class of osmolytes. Paul and co-workers ${ }^{37}$ have suggested in their work on TMAO osmolyte that the hydrophobic methane molecules are compatible with the methyl groups of TMAO and can substitute methyl groups in TMAO molecules. There are differences in the effect of these two osmolytes on preferential solvation of methane molecules. There is a negligible effect of TMAO on the hydrophobic association of methane ${ }^{37}$ while sarcosine enhances the hydrophobic association of methane i.e., salting-out of methane. Glycine-betaine also enhances the association of methane i.e., saltingout of methane. ${ }^{66}$ The preferential solvation of methane by water over sarcosine is supported by the RCN values. The preferential binding constants for methane in water-sarcosine further support this observation. The analysis of RDFs by KB integrals also indicate the preferential solvation by water (figure 8 ). The strong association between water and sarcosine (figure S5) is also responsible for the reduction of local densities of sarcosine around methane.

The hydrophobic association between methane molecules is expected to be more because of preferential methane-water interaction over methane-sarcosine. The values of the equilibrium constants obtained indicate enhanced association of methane molecules.

The two synergistic effects in water-sarcosine, namely, an increase in hydrophobic association due to preferential methane-water interaction in the presence 
of sarcosine and methane-methyl group compatibility causes 'salting out' of methane molecules in the mixture.

The presence of sarcosine affects water structure. The $\mathrm{O}_{\mathrm{W}}-\mathrm{O}_{\mathrm{W}}$ RDFs in water and water-sarcosine mixtures (figure 6) show their first peak at $0.28 \mathrm{~nm}$ (for hydrogen bonded first neighbors) and second peak at $0.45 \mathrm{~nm}$ (corresponding to the tetrahedrally located second neighbors). Presence of sarcosine as well as glycine-betaine enhance the height of first peak of $\mathrm{O}_{\mathrm{W}^{-}}$ $\mathrm{O}_{\mathrm{W}}$ RDFs. However sarcosine decreases the depth of the first minimum while glycine-betaine increases the depth. ${ }^{66}$ The location of peaks and heights in the RDFs of water match with the earlier reported values. ${ }^{38}$ This synergistic effect of sarcosine can be further explained by analyzing hydrogen bond properties in the watersarcosine mixture. The addition of sarcosine reduces the average number of hydrogen bonds per water molecule (table 9) as the number density of water decreases considerably but increases the lifetimes of hydrogen bonds (table S5 of Supplementary Information). Similar observations have been reported earlier for aqueous solutions of osmolytes, where enhancements in the lifetimes of hydrogen bonds have been found. ${ }^{24,67,69}$

\section{Conclusions}

We have studied the hydrophobic association and solvation of methane molecules in aqueous solutions of urea and sarcosine by using MD simulations. We have computed the potentials of mean force between methane molecules in water, water-sa, water-urea and waterurea-sa mixtures. From the analysis of PMFs, it is observed that the association methane is enhanced on the addition of these osmolytes. These observations are well supported by calculation of equilibrium constants. Association of methane is dominated by entropy and favored by enthalpy in these mixtures. Solvation of methane is stabilized by enthalpy and destabilized by entropy. The calculated solvation free energies of methane in these mixtures show that methane is less soluble in the mixtures of urea and sarcosine than in water. The solubility is the least in water-urea-sa mixture.

Analysis of RDFs suggests that addition of both the osmolytes enhances local water structure. The strong association of water with urea and sarcosine is well supported by the values of diffusion constants obtained for water. Besides RDFs, we have also calculated RCNs, KBI and ECNs of solvent and co-solvent around methane molecules to understand preferential solvation of methane. Such studies provide an insight into 'salting in' and 'salting out' of solute molecules.
We find that both urea and sarcosine are selectively reduced from methane surface in the mixtures of osmolytes because of strong association between watersarcosine and water-urea. Therefore, methane is preferentially solvated by water molecules in the mixtures of osmolytes. The reduction of the local densities of both urea and sarcosine around the methane suggest that both urea and sarcosine increase the association of methane molecules i.e., 'salting out' of methane. It is interesting that the osmolytes in our studies namely, urea and sarcosine belong to different classes which show opposite effect on association (salting-out) and solvation (salting-in) of larger molecules. It would be desirable to study larger alkanes and biological entities such as proteins in aqueous mixtures containing sarcosine and urea. Studies of such systems will assist in understanding the mechanism of important physical processes of solubility and the role of osmolytes in stabilizing and denaturing proteins.

\section{Supplementary Information (SI)}

The positions and free energies of CM, TS and SSM and thermodynamic quantities, lifetimes of hydrogen bonds and bond dissociation energies of hydrogen bonds of water in the bulk in $\mathrm{I}_{\mathrm{w}}, \mathrm{II}_{\mathrm{w}-\mathrm{sa}}, \mathrm{III}_{\mathrm{w}-\mathrm{ua}}$ and $\mathrm{IV}_{\mathrm{w}-\mathrm{ua}-\mathrm{sa}}$ are given in the tables $\mathrm{S} 1$ to $\mathrm{S} 5$. The error bars in the PMF curves, radial distribution functions, excess coordination numbers and hydrogen bond time correlation functions are shown in figures S1 to S5. All the Figures from $\mathrm{S} 1$ to S5 and Tables from S1 to S5 are given in the supplementary information. This material is available free of charge via the Internet at www.ias.ac.in/chemsci.

\section{Acknowledgements}

We would like to express our gratitude to IIT Bombay for providing us with the High Performance Computing Facility and the Department of Chemistry, IIT Bombay for providing research facilities. MKD thanks UGC, Government of India for a Senior Research Fellowship. AC thanks the support received through the KVPY Fellowship funded by DST, Government of India.

\section{References}

1. Choudhury N and Pettitt B M 2007 J. Am. Chem. Soc. 1294847

2. Tanford C 1997 Protein Sci. 61358

3. Bennion B J and Daggett V 2003 Proc Natl. Acad. Sci. U.S.A. 1005142

4. Caballero-Herrera A, Nordstrand K, Berndt K D and Nilsson L 2005 Biophys. J 9842 
5. Mountain R D and Thirumalai D 2003 J. Am. Chem. Soc. 1251950

6. Timasheff S N 1993 Annu. Rev. Biophys. Biomol. Struct. 2267

7. Bolen D W and Rose G D 2008 Annu. Rev. Biochem. 77 339

8. Rossky P J 2008 Proc. Natl. Acad. Sci. U.S.A. 10516825

9. Moeser B and Horinek D 2014 J. Phys. Chem. B 118107

10. Yancey P H and Somerot G N 1979 Biochemical Journal 183317

11. Withers P C and Guppy M 1996 J. Exp. Biol. 199 1809

12. Holthauzen L M F and Bolen D W 2007 Protein Sci. 16 293

13. Venkatesu P, Lee Ming-Jer and Lin Ho-mu 2009 J. Phys. Chem. B 1135327

14. Chandler D and Pratt R 1997 J. Chem. Phys. 673683

15. Berne B J, Rao M and Pangali C 1979 J. Chem. Phys. 712975

16. Jorgensen et al. 1988 J. Chem. Phys. 893742

17. Berne B J et al. 1979 J. Chem. Phys. 712982

18. Dang L X 1994 J. Chem. Phys. 1009032

19. Pratt L R, Merchant S and Asthagiri D $2008 \mathrm{~J}$. Chem. Phys. 128244512

20. Bennion B J and Daggett V 2003 Proc. Natl. Acad. Sci. U.S.A. 1005142

21. Mountain R D and Thirumalai D 2003 J. Am. Chem. Soc. 1251950

22. Wang A and Bolen D W 1997 Biochemistry 369101

23. Liu Y and Bolen D W 1995 Biochemistry 3412884

24. Baskakov I and Bolen D W 1998 J. Biol. Chem. 273 4831

25. Bolen D W and Baskakov I 2001 J. Mol. Biol. 310955

26. Bennion B J and Daggett V 2004 Proc. Natl. Acad. Sci. U.S.A. 1016433

27. Oostenbrink C and van Gunsteren W F 2005 Phys. Chem. Chem. Phys. 753

28. Lee M -E and van der Vegt N F A 2006 J. Am. Chem. Soc. 1284948

29. Zangi R, Zhou R and Berne B J 2009 J. Am. Chem. Soc. 1311535

30. Thomas A S and Elcock A H 2007 J. Am. Chem. Soc. 12914887

31. Docherty H, Galindo A, Sanz E and Vega C $2007 \mathrm{~J}$. Phys. Chem. B 1118993

32. Shimizu S and Chan H S 2001 J. Am. Chem. Soc. 123 2083

33. Shimizu S and Chan H S 2002 Proteins 4815

34. Shimizu S and Chan H S 2002 Proteins 49560

35. Ikeguchi M, Nakamura S and Shimizu K $2001 \mathrm{~J}$. Am. Chem. Soc. 123677

36. Trzesniak D, van der Vegt N F A and van Gunsteren W F 2004 Phys. Chem. Chem. Phys. 6697

37. Paul S and Sarma R 2012 J. Phys. Chem. B 1162831

38. Kishore N and Kumar N 2013 Biophys. Chem. 1719
39. Garde S, Sarupriya S and Athawale M 2008 J. Phys. Chem. B 1125661

40. Pettitt B and Choudhary N 2006 J. Phys. Chem. B 110 8459

41. Hess B, Kutzner C, van der Spoel D and Lindahl E 2008 J. Chem. Theory Comput. 4435

42. Essmann U, Perera L, Berkowitz M L, Darden T, Lee H and Pedersen L G A 1995 J. Chem. Phys. 1038577

43. Berendsen H J C, Postma J P M, van Gunsteren W F, DiNola A and Haak J R 1984 J. Chem. Phys. 813684

44. Hess B, Bekker H, Berendsen H J C and Fraaijel J G E M 1997 J. Comput. Chem. 181463

45. Bussi G, Donadio D and Parrinello M 2007 J. Chem. Phys. 126014101

46. Berendsen H J C, Grigera J R and Straatsma T P J 1987 J. Phys. Chem. 916269

47. Jorgensen W L, Maxwell D S and Tirado-Rives J 1996 J. Am. Chem. Soc. 11811225

48. Jorgensen W L and McDonald N A 1998 Theochem. 424 145

49. Jorgensen W L and McDonald N A 1998 J. Phys. Chem. B 1028049

50. Rizzo R C and Jorgensen W L 1999 J. Am. Chem. Soc. 1214827

51. Price M L, Ostrovsky D and Jorgensen W L $2001 \mathrm{~J}$. Comp. Chem. 221340

52. Watkins E K and Jorgensen W L 2001 J. Phys. Chem. A $\mathbf{1 0 5} 4118$

53. Kaminski G A, Friesner R A, Tirado-Rives J and Jorgensen W L 2001 J. Phys. Chem. B 1056474

54. Frisch M J, et al. 2009 Gaussian 09, Revision A.02 (Gaussian, Inc.: Wallingford CT)

55. Kahn K and Bruice T C 2002 J. Comput. Chem. 23977

56. Jorgensen W L and Gao J J 1986 J. Phys. Chem. 902174

57. Singh U C and Kollman P A 1984 J. Comput. Chem. 5 129

58. Martinez L, Andrade R, Birgin E G and Martinez J M 2009 J. Comput. Chem. 302157

59. Parrinello M and Rahman A 1981 J. Appl. Phys. 527182

60. Nose S and Klein M L 1983 Mol. Phys. 501055

61. Peter C, Oostenbrink C, van dorp A and van Gunsteren W F 2004 J. Chem. Phys. 1202652

62. Ben-Naim A 1987 In Solvation Thermodynamics (New York: Plenum Press)

63. Widom B 1963 J. Chem. Phys. 392808

64. Kirkwood J G and Buff F P 1951 J. Chem. Phys. 19774

65. Schurr J M, Rangel D P and Aragon S R 2005 Biophys. J. 892258

66. Dixit M K, Siddique A A and Tembe B L 2015 J. Phys. Chem. B 11910941

67. Wei H, Fan Y and Gao Y Q 2010 J. Phys. Chem. B114 557

68. Luzar A and Chandler D 1996 Nature 37955

69. Athawale M V, Dordick J S and Garde S 2005 Biophys. J. 89858 